\title{
Cross-border health care represents a key issue in the field of rare diseases
}

\author{
Paola Facchin \\ From 5th European Conference on Rare Diseases (ECRD 2010) \\ Krakow, Poland. 13-15 May 2010
}

The Veneto Region, north-east of Italy, 4.7 million inhabitants, is interested by this phenomenon, both for its geographical position, a hinge between Eastern and Western European countries, and for the presence of specialised health care services, most of which are specifically addressed to RD patients.

The aim of the study is to analyse patients' mobility in Veneto Region, especially from Eastern European countries, describe the established RD care network, and how it was successfully extended to other Italian Regions and its possible scalability to other neighbouring countries.

In 2009, 17,769 RD patients were cared for in our Region, 16\% coming from other Italian Regions. Foreign RD patients were $766,3.7 \%$ of all the patients coming from abroad and $4.3 \%$ of all RD patients followed in the area.

Comparing these patients to Italian RD patients, the paediatric component is more represented (44\% vs $30.3 \%)$. Congenital malformations are the most frequent diagnoses (16.5\%), followed by metabolic diseases (9.2\%). Foreign RD patients move to undergo very specialised interventions, i.e. heart surgery $(n=52)$, organ transplantations $(n=36)$, or to obtain second opinions. $67.5 \%$ come from European countries, in particular 49.2\% from Eastern countries, both EU and non-EU.

These patients are referred to Centres of Expertise, officially identified, which are part of a wider interregional network, based on the collaboration between specialised Centres and primary care services. The continuity of the care process is supported by the use of shareable patients' electronic records in neighbouring Regions and by the elaboration of common management protocols for specific RD.

Correspondence: facchin@pediatria.unipd.it

Epidemiology and Community Medicine Unit, Paediatrics Department, University of Padua, Via Giustiniani, 335128 Padua, Italy

๑) 2010 Facchin; licensee BioMed Central Ltd.
RD patients' mobility should lead to the development of common policies and services addressed to these patients involving neighbouring Regions/countries. Preliminary intercourses already occurred with Slovenia in order to share best practices in the complex field of RD patients' care.

Published: 19 October 2010

doi:10.1186/1750-1172-5-S1-031

Cite this article as: Facchin: Cross-border health care represents a key issue in the field of rare diseases. Orphanet Journal of Rare Diseases 2010 5(Suppl 1):O31.
Submit your next manuscript to BioMed Central and take full advantage of:

- Convenient online submission

- Thorough peer review

- No space constraints or color figure charges

- Immediate publication on acceptance

- Inclusion in PubMed, CAS, Scopus and Google Scholar

- Research which is freely available for redistribution

Submit your manuscript at www.biomedcentral.com/submit
C Biomed Central 